\title{
DIREITOS UNIVERSAIS OU AMERICANIZAÇÃO TOTAL?
}

\author{
José A. Lindgren-Alves \\ é membro do Comitê para a Eliminação da Discriminação Racial (ONU, Genebra, 2002-2017) e, \\ atualmente, membro do Comitê Assessor do Conselho de Direitos Humanos das \\ Nações Unidas (Genebra).Genebra, Suíça.E-mail: lindgrenja@aol.com
}

Orcid: 0000-0001-6258-6201

http://dx.doi.org/10.1590/0102-017043/108

\section{Prólogo: explicações necessárias}

Depois de duas décadas de atuação isolada, advertindo colegas e outros atores na Organização das Nações Unidas (ONU) sobre os efeitos contraproducentes do maximalismo das diferenças nas lutas contra discriminações, vejo que foi necessária a chegada de Donald Trump à Casa Branca para que analistas de esquerda vissem e dissessem que a obsessão com identidades imutáveis é intrinsecamente "de direita", mais opressora do que libertária.

Conquanto Marx se mostrasse oposto à ideia de diferenças sociais não classistas, especialmente na obra pela qual foi declarado "antissemita" (Marx, 2010), a ideia de comunidade de identificação necessária à autorrealização do indivíduo firmou-se no final do século XX. Começou na academia e foi por ela transmitida aos movimentos sociais, com apoio no discurso dos direitos humanos, servindo de base teórica ao multiculturalismo que se impunha por influência americana. Somente pensadores provocativos, como Slavoj Zizek e Régis Debray, na Europa, e professores radicais americanos, como Noam Chomsky e Camille Paglia, assumiam isoladamente 
sua descrença, apontando aspectos absurdos da onda cultural dominante. Os demais evitavam fazê-lo para não parecerem reacionários, de direita, racistas, homofóbicos, machistas, antissemitas, islamofóbicos, eurocêntricos e outras qualificações desairosas. Inovador nesse cenário restritivo foi, recentemente, o professor Mark Lilla, da Universidade de Columbia, pragmático perspicaz, focalizado e bem americano. Em 2017, pouco depois da eleição de Trump, teve a coragem, inusitada no meio acadêmico de esquerda, de dizer que, nos Estados Unidos, "cada passo em frente da consciência liberal identitária constituiu um passo para trás da consciência liberal politica" (Lilla, 2018, p. 16, grifo do autor). Nem teve maiores pruridos para concluir, pondo o dedo na ferida:

Hoje em dia, e não sem justeza, o liberalismo é considerado uma crença professada acima de tudo pelas elites urbanas cultas, isoladas do resto do país, que olham para os assuntos quotidianos através do prisma identitário, esforçando-se para sustentar e alimentar movimentos hipersensíveis, que dissipam, em vez de consolidar, as energias do que ainda resta da esquerda. (Lilla, 2018, p. 16) ${ }^{1}$

Tanto Lilla, liberal realista, como o marxista Zizek, rotulado de "pop star da filosofia", como o ex-revolucionário Régis Debray, acusado de "direitismo", e a velha expoente da contracultura, Camille Paglia, detestada pelas feministas, têm sido rejeitados pela esquerda intelectual dominante. O senador Bernie Sanders também pensa e age em linha não identitária - já o fazia em 2016, tendo provavelmente por isso perdido a indicação do Partido Democrata para

\footnotetext{
1 O livro The once and future liberal: after identity politics foi traduzido em Portugal com o título adaptado De esquerda, agora e sempre: para além das políticas identitárias lembrando que somente nos Estados Unidos "liberal" é "de esquerda". Na tradução brasileira, o título O progressista de ontem e o de amanhã parece ir contra a mensagem que Lilla quer dar.
} 
Hillary Clinton, emblemática do establishment "progressista". Para mim, diplomata brasileiro aposentado ainda individualmente atuante no sistema de direitos humanos, difícil é não parecer agora, com minhas posições, cooptado pelo grupo ideológico no poder em Brasília. Perante os desconfiados, posso invocar em legítima defesa os textos que tenho escrito desde antes da virada do século. ${ }^{2}$ Neles se pode ver que sempre trabalhei pelos direitos universais, inclusive pelas condições de igualdade real para as minorias, alertando para excessos inúteis e contraproducentes. Incorro, então, em outro risco, hoje mais perigoso: de ser encarado como integrante de uma conspiração "globalista" gramsciana, anticristã e antiocidental, como pensa a lunatic fringe ("franja lunática”) da sociedade americana, ora popularizada no Brasil, com ares de coisa séria e efeitos desastrosos.

Não devo, porém, no percurso que tracei para este texto, pôr o carro na frente dos bois. Conforme o resumo do projeto, incumbe-me explicitar antes meu entendimento sobre aquilo que o presidente Trump representa como desafio para o sistema internacional dos direitos humanos existente. É isso que agora procurarei fazer.

\section{0 papel dos Estados Unidos no sistema de direitos humanos}

Segundo ditado francês menos otimista que os "males que vêm pra bem”, “à quelque chose malheur est bon”: para alguma coisa a infelicidade é boa. Talvez a eleição de Trump tenha servido, como ponto positivo, para mostrar o erro de professores brasileiros ao ensinarem que a asserção dos direitos humanos no mundo se deve aos Estados Unidos.

\footnotetext{
2 Dentre os quais cito aqueles constantes de meu livro Os direitos humanos na pós-modernidade, cujo capítulo 5 já se intitulava, na forma de indagação, "Excessos do culturalismo: pós-modernidade ou americanização da esquerda?" (Lindgren-Alves, 2005, pp. 89-110). O último livro congênere, com textos que remontam de 2017 a 1998, chama-se É preciso salvar os direitos humanos! (Lindgren-Alves, 2018b).
} 
Longe de mim negar a importância que os Estados Unidos sempre tiveram nesse campo. Mas conferir-lhes papel determinante na disseminação planetária de tais direitos, além de endossar distorções pelas quais eles são responsáveis, é desconsiderar a importância de outros atores, socialistas e social-democratas, propulsores dos direitos econômicos e sociais, que criaram as condições necessárias para a universalização teórica dos direitos humanos. É, sobretudo, reproduzir de maneira acrítica aquilo que os próprios Estados Unidos ensinam. E quando digo aqui "os Estados Unidos”, não me refiro apenas aos porta-vozes de governo. Refiro-me também aos scholars e jornalistas, aos políticos republicanos e democratas, aos movimentos sociais, às organizações não governamentais (ONG), às foundations, a todos os militantes de lá. Essa ampla convicção egocêntrica, que outros, de fora, automaticamente estimulam, não corresponde à realidade vivida.

20 Para entender tal fato, histórico, não é preciso concentrar atenções somente nas políticas e posturas do presidente atual, por mais que estas agravem atitudes nefastas antigas e prejudiquem o sistema de direitos humanos construído em setenta anos.

\section{O sistema de direitos humanos antes de Trump}

Durante a maior parte do século XX, falar em direitos humanos era falar dos Estados Unidos. Para isso havia razões importantes. Foram eles que, depois da entrada do Exército Vermelho em Berlim, lideraram a libertação da Europa Ocidental e, com as bombas atômicas lançadas em Hiroshima e Nagasaki, terminaram a Segunda Guerra Mundial. Foram eles que abrigaram os judeus alemães mais brilhantes e numerosos, escapados do Holocausto nazista. Foram eles que formaram, com os Aliados, o Tribunal de Nuremberg para julgar a liderança hitlerista, dando origem ao conceito de crime contra a humanidade. Foram sugestões da sociedade civil 
norte-americana que promoveram a inclusão dos direitos humanos na Carta das Nações Unidas. E foi sua ex-primeira-dama, Eleanor Roosevelt, quem presidiu a comissão designada para redigir o anteprojeto da Declaração Universal de Direitos Humanos, proclamada pela Assembleia Geral em 10 de dezembro de 1948, em Paris.

Não foi, porém, por obra e graça dos Estados Unidos que aquele documento se tornou farol das lutas pela liberdade e igualdade no mundo. Ainda na fase preparatória de sua elaboração, foram os Estados Unidos, contra a vontade de Eleanor Roosevelt, que primeiro se opuseram à ideia de um tratado que lhes impusesse obrigações domésticas, optando por um documento mais fraco: uma simples declaração. Foi também pela recusa dos Estados Unidos em reconhecer direitos econômicos, sociais e culturais que a continuação das negociações sobre um tratado de natureza cogente prosseguiu em duas vias, preparando instrumentos separados. Os dois Pactos Internacionais, de Direitos Civis e Políticos e de Direitos Econômicos, Sociais e Culturais, complementação jurídica da Declaração Universal, levaram duas décadas em negociação: aprovados em 1966, esperariam mais dez anos, até 1976, para entrar internacionalmente em vigor. E o país somente ratificou o pacto sobre direitos civis e políticos no contexto de preparação para a Conferência Mundial de Direitos Humanos, de 1993, em Viena, não havendo nunca aderido ao pacto irmão.

Os Estados Unidos são, até hoje, um dos estados que menos ratificaram instrumentos internacionais de direitos humanos, apenas cinco no âmbito das Nações Unidas, a saber: a Convenção sobre a Eliminação da Discriminação Racial, o Pacto de Direitos Civis e Políticos, a Convenção contra a Tortura, o protocolo adicional à Convenção sobre os Direitos da Criança, relativo ao envolvimento de crianças em conflitos armados, e o protocolo sobre a venda de crianças, a prostituição e a pornografia infantis, adicional à 
mesma convenção - esta assinada por eles em 1995, mas não ratificada até hoje. Se isso, por um lado, pode revelar seriedade, no sentido de que o estado não adere a nada que não possa ou não deseje cumprir, por outro, mais expressivo, essa relutância perene decorre do autoconferido "excepcionalismo", que põe o país acima daquilo que ele próprio exige dos demais. Essa é também a causa principista de sua relutância em aceitar visita de inspetores de fora, contornada em alguns casos somente há pouco tempo. Há que assinalar, porém, em favor da hipótese de coerência, que, uma vez ratificado o instrumento internacional normativo, os Estados Unidos vinham cumprindo, tanto nos tempos de George W. Bush como nos de Barack Obama, a regra de apresentação de relatórios periódicos sobre sua situação aos órgãos de supervisão competentes. ${ }^{3}$

Enquanto todas essas dificuldades autoimpostas para a adesão ao direito internacional de direitos humanos podem ser “justificadas” pela visão altaneira da soberania própria, de uma superpotência, mais inexplicável é a hipocrisia que sempre pautou a mesma superpotência na antiga Comissão, hoje Conselho, de Direitos Humanos (CDH) da ONU. A duplicidade de valores na formulação de condenações contra adversários - como o Iraque de Saddam Hussein, ou o Irã depois da queda do xá, e particularmente Cuba, mas não a antiga União Soviética, ou a Rússia de Putin, ou regimes de direita é exasperante. Isso pode ter ajudado as vítimas de violações daquelas áreas específicas. Não poderia nunca, contudo, servir de fator convincente para a disseminação planetária dos direitos humanos. Mais útil nesse sentido foi, no passado, a atuação de entidades privadas respeitáveis, como a Anistia

3 Embora todos esses fatos tenham sido amplamente citados na literatura sobre o assunto, confirmei-os no site do Alto Comissariado das Nações Unidas para os Direitos Humanos (www.ohchr.org). Quanto à apresentação de relatórios americanos no período Bush e no período Obama, eu próprio participei de seu exame na qualidade de membro do Comitê para a Eliminação da Discriminação Racial (Cerd). 
Internacional, com sede em Londres, a Anti-Slavery Society, britânica, e a Human Rights Watch, americana.

De todos os presidentes dos Estados Unidos durante a Guerra Fria, o único que pretendeu atribuir aos direitos humanos valor para inspirar sua política externa foi o democrata Jimmy Carter. Tentou, mas não conseguiu grande êxito. Logrou aderir à Convenção Americana (Pacto de San José), sem reconhecer a competência judicial da Corte Interamericana de Direitos Humanos - como, aliás, o Brasil, até 1998. Incentivou a divulgação de relatórios anuais pelo Departamento de Estado sobre todos os países, numa atitude certamente arrogante, mas útil. Provocou estremecimentos nas relações com regimes militares da América Latina - que, em retrospecto, se revelaram positivos, em longo prazo, nos processos de redemocratização regional -, sendo, porém, fragorosamente derrotado pelos efeitos da revolução xiita iraniana de 1979, com o humilhante aprisionamento dos funcionários da embaixada norte-americana em Teerã. Foi vencido internamente, ao tentar reeleição, pelo concorrente republicano Ronald Reagan, antípoda na matéria.

Com Reagan nos Estados Unidos e Margaret Thatcher na Inglaterra se iniciaria a fase de neoliberalismo econômico que começou a desmontar as conquistas trabalhistas na Europa e depois atingiria, com maior profundidade, níveis planetários. Começou, também, o fim da confrontação ideológica entre Washington e Moscou, graças à ascensão de Mikhail Gorbachev ao cargo de secretário-geral do Partido Comunista da União Soviética. As políticas de distensão, reestruturação e transparência adotadas por Gorbachev culminariam com a autodissolução dos regimes comunistas em todo o Leste Europeu, inclusive da própria URSS. Nessa mesma fase, após a queda icônica do Muro de Berlim, em novembro de 1989, quando emergiam as etnias como base para o nacionalismo e as guerras de independência de ex-repúblicas soviéticas e iugoslavas, ocorriam igualmente o fim do apartheid na África 
do Sul, para o qual a política apaziguadora americana pouco contribuiu, e a redemocratização de toda a América Latina, fenômenos conjuntamente influentes na grande valorização dos direitos humanos da década de 1990.

A nova fase de estreitamento de relações Leste-Oeste e a derrocada de vários regimes totalitários e autoritários deram impulso inédito ao movimento em prol dos direitos humanos em todo o mundo e levaram à realização da Conferência Mundial de 1993, em Viena, sugerida por ONGs, encampada por países de todos os grupos regionais e patrocinada pela ONU, que se tornou verdadeiro divisor de águas no processo de afirmação desse novo tema global. Foi nela que se plantou a raiz do Alto Comissariado das Nações Unidas para os Direitos Humanos (ACNUDH) e uma recomendação pioneira à Comissão de Direito Internacional em matéria de crimes contra a humanidade, que impulsionou a criação do Tribunal Penal Internacional. ${ }^{4} \mathrm{Na}$ preparação e 24 na realização da Conferência de Viena, inclusive na formulação que permitiu a aprovação dessas propostas, a atuação da América Latina foi decisiva, certamente mais importante que a atividade confrontacional dos Estados Unidos. ${ }^{5}$ É dela que advém, para o bem e para o mal, a configuração atual, expandida, do sistema internacional de direitos humanos.

Ao longo dos anos 1990, em virtude da alegada vitória da democracia liberal sobre o declarado "socialismo real", os países ocidentais desenvolvidos tornaram-se extremamente ativos em propostas na área dos direitos humanos. O aparente "triunfo do Ocidente", sob liderança americana, com Ronald Reagan e George H. W. Bush (pai), beneficiou particularmente a imagem do governo do presidente Bill

\footnotetext{
4 Parágrafos 18 e 92, respectivamente, do Programa de Ação de Viena.

${ }^{5}$ Como já muito escrevi sobre a Conferência de Viena, creio ser desnecessário reiterar aqui as análises desse evento e de suas consequências. Entre elas, permito-me referir, por exemplo, meus livros Os direitos humanos como tema global (Lindgren-Alves, 2011) e $A$ década das conferências (Lindgren-Alves, 2018a).
} 
Clinton como propulsor de tais direitos. Seguindo a tradição liberal dos democratas desde John Kennedy e Lyndon Johnson, Clinton fez gestos de solidariedade com minorias internas e externas. Foi ele que, em preparação ou consequência da Conferência de Viena de 1993, conseguiu, em 1992 e 1994, vencer as barreiras domésticas para ratificar os poucos tratados de que os Estados Unidos são parte. Não o conseguiu, porém, para as Convenções sobre a Eliminação de Todas as Formas de Discriminação contra a Mulher e sobre os Direitos da Criança.

Aqui cabe um parêntesis para uma observação sempre ausente nas análises do sistema, concentradas na "importância incomparável" dos Estados Unidos e de seus principais aliados: desde a redemocratização da política, os governos da América Latina recorriam à $\mathrm{CDH}$ como instrumento de apoio aos esforços internos em favor dos direitos humanos, que se iam institucionalizando na respectiva jurisdição. ${ }^{6}$ Ou seja, demonstravam um apreço pelo trabalho desse órgão que outras áreas não tinham. Esse fato, comprovável nos discursos do item concernente a violações, ${ }^{7}$ contrastava com seu uso invariável pelo Grupo Ocidental, em particular pelos Estados Unidos, apenas para condenar terceiros.

Depois de Bill Clinton, os direitos humanos sofreram enorme retrocesso em função das políticas antiterrorismo de George W. Bush (filho). Disso falarei adiante, em conjunção com o período de Donald Trump. No intervalo de oito anos entre esses dois presidentes republicanos, o democrata Barack Obama foi, depois de Jimmy Carter, o presidente que mais seriamente tentou atuar em favor dos direitos

\footnotetext{
${ }^{6}$ Recordo-me que minha primeira ação substantiva como delegado nas Nações Unidas, em 1985, foi conseguir autorização para respaldar um projeto da Argentina solicitando o fim da confidencialidade das comunicações contra ela apresentadas à $\mathrm{CDH}$ durante o regime militar.

7 A primeira intervenção do Brasil nessa linha foi a de 1991, dentro do item 12 da 47a Sessão da Comissão, lida pelo embaixador Rubens Ricupero. Ver trechos principais e interpretação em Lindgren-Alves (2011, pp. 95-96).
} 
humanos, dentro e fora do país. Mas sua ação em política externa, questionável em muitas áreas, esteve sempre limitada pela herança de Bush, pelas barreiras republicanas e por outras injunções domésticas.

Que os aspectos da política americana de direitos humanos aqui lembrados possam ter contribuído decisivamente para a asserção de tais direitos e liberdades no mundo é duvidoso. Até porque, se o tivessem, os direitos disseminados seriam apenas alguns, civis e políticos. Os EUA nunca reconheceram os direitos econômicos e sociais, embora seja o primeiro país a dividir a própria população por identidades forçadas na distribuição de verbas. Mais importante do que o Estado americano para o sistema internacional terá sido a atuação da sociedade civil, das ONGs e das entidades de apoio a grupos específicos. É por causa delas como modelo e influência direta nas entidades homólogas e no secretariado das instituições competentes, assim como das foundations que financiam projetos - que os direitos, depois de Viena, ultrapassaram o nível de mero discurso. Voltados quase sempre para mulheres e minorias específicas, sejam elas raciais ou étnicas, sejam universais, como as crianças, os portadores de deficiências ou as chamadas minorias de gênero (LGBTI), tais projetos propõem e apoiam políticas públicas, principalmente no campo dos direitos econômicos, sociais e culturais.

Quando o governo Trump decidiu deixar o $\mathrm{CDH}$, em junho de 2018, temeu-se que isso viesse a ter repercussões profundas no sistema. Pelo que pude apurar, não teve, pelo menos até fevereiro de 2019. Essa não foi a primeira vez que os Estados Unidos se desligaram do principal órgão político de direitos humanos, que já havia sobrevivido incólume a decisão parecida na época de George W. Bush. Mais graves foram, e ainda são, outras práticas e decisões que envolvem violações deliberadas, tomadas tanto pelos "neoconservadores" de Bush como pela personalidade arrogante de Trump. 


\section{Participação e saída dos Estados Unidos do sistema internacional de direitos humanos}

O primeiro afastamento dos Estados Unidos do principal órgão da ONU com competência na matéria de direitos humanos ocorreu pelos mesmos motivos alegados em 2018: o tratamento dispensado a Israel por sua atuação nos territórios palestinos ocupados, diferenciado, em item separado da agenda, dos demais países acusados de violações; e a participação nesse órgão de Estados considerados violadores contumazes de direitos de sua respectiva população, como Cuba, Sudão e o Iraque de Saddam Hussein (hoje China, Cuba e Venezuela). Com base nessas alegações e em outros defeitos que viam na então Comissão dos Direitos Humanos, resumidos na impossibilidade de determinar seu comportamento, os Estados Unidos lideraram o grupo de países ocidentais com propostas de reforma do órgão. As negociações se desenvolveram entre 1997 e 2006, tendo de um lado os ocidentais desenvolvidos e, de outro, países em desenvolvimento reunidos com a China, todos os quais criticavam a "politização" da Comissão, em linhas opostas. Em 2006, não vendo suas propostas aceitas, os Estados Unidos de Bush decidiram desvincular-se do processo e não se candidatar ao órgão que passaria a ser Conselho de Direitos Humanos, de nível hierárquico mais elevado, chegando a votar contra a resolução respectiva da Assembleia Geral da ONU. ${ }^{8}$ Em função disso, e da reiteração da decisão de não concorrer em 2007 e 2008, passaram a acompanhar os trabalhos na categoria de observadores até 2009, quando, já na administração de Obama, voltaram a eleger-se.

Se as razões alegadas para a saída do Conselho e, antes, da Comissão eram as mesmas (Pompeo e Haley, 2018), igualmente importantes para a rejeição da reforma de 2006

\footnotetext{
8 Ver intervenção do então embaixador na ONU, John Bolton, ministro da defesa de Trump, em explicação de voto (Bolton, 2006). Todas as violações e defeitos que ele atribui a terceiros se poderiam aplicar aos próprios Estados Unidos, especialmente naqueles momentos tenebrosos da "Guerra ao Terror" e da ocupação do Iraque.
} 
podem ter sido as críticas que o governo Bush vinha recebendo no mundo inteiro, inclusive de alguns mecanismos temáticos e órgãos de tratados, por sua atuação no Iraque e na "Guerra ao Terror": aplicação regular de torturas como meio de interrogatório - como o famoso waterboarding -, abusos escandalosos fotografados no presídio Abu Ghraib, detenções arbitrárias de suspeitos em Guantánamo, e as renditions - entrega de prisioneiros para interrogatório em países com regras menos estritas. Todos esses elementos e outros, como gestões bilaterais para garantir a não submissão de americanos ao Tribunal Penal Internacional (que nunca reconheceram), assim como a irritante utilização seletiva da velha Comissão e do novo Conselho de Direitos Humanos contra países insignificantes ou inimigos estratégicos, fundamentavam a possibilidade de que, caso concorressem em disputa de vaga, os EUA não fossem eleitos. Sabe-se, a propósito, que em 2009, já no governo Obama, quando os Estados Unidos se apresentaram para uma das três vagas destinadas ao Grupo Ocidental, com certeza de eleição pela igualdade do número de candidatos e de lugares, tiveram menos votos que os outros dois postulantes: Bélgica e Noruega (Hernandez e Rocha, 2018).

Embora o governo Bush se tenha pautado pelo unilateralismo intervencionista, com graves repercussões para a credibilidade de todo o sistema e para a própria ideia dos direitos e das liberdades fundamentais, a não participação na criação do novo CDH não implicou seu afastamento completo. Além de continuar financiando o que antes financiava, o país acompanhou de perto as atividades e as apresentações dos informes de todos os países na Revisão Periódica Universal, principal inovação adotada desde 2007, não seletiva porque cobrada de todos os membros das Nações Unidas. Coube ao governo Obama, com o país já reintegrado formalmente ao sistema, apresentar os dois primeiros relatórios americanos dentro desse mecanismo. 
Enquanto o presidente Obama foi valorizador real dos direitos humanos com sentido universalista, como comprovam suas iniciativas internas, especialmente na área da saúde, seu universalismo não era compartilhado pela sociedade civil organizada, cada dia mais voltada para o particularismo das identidades. Isso se sentia desde o início do governo, quando, malgrado gestos expressivos do presidente, lideranças radicais do movimento negro criticavam-no por não se assumir como afro-americano diferencialista. Tampouco ajudou sua escolha de Hillary Clinton como secretária de Estado, continuadora do intervencionismo militar dito "humanitário" de seu marido e dos "falcões" de Bush, a qual, diferentemente de Obama, havia apoiado no Senado a invasão do Iraque em 2002. Bem recebida pelos ditos "progressistas" e funcionários do sistema, crescentemente transformado em cadeia de transmissão das ONGs, Hillary pouco contribuiu para a visão dos Estados Unidos como real defensor dos direitos humanos.

Embora a instrumentalização do sistema sempre tenha caracterizado a política americana de direitos humanos, como a de quase todos os países do Grupo Ocidental, os abusos da era Bush, concentrados em suspeitos de terrorismo islâmico, ainda podiam ser, até certo ponto, justificados com o trauma representado pelo Onze de Setembro. Nada dessa gravidade amparava os excessos do candidato multimilionário Donald Trump, contestador extremado dos democratas, que havia posto em causa a própria nacionalidade do antecessor "negro", de nome árabe e posições liberais mais sólidas do que a média. A não ser, evidentemente, seu extraordinário faro oportunista para as insatisfações do cidadão americano comum, religioso e conservador.

Com foco naqueles que haviam perdido empregos pelo deslocamento de indústrias, nos bolsões brancos supremacistas do interior e nos fundamentalistas protestantes e católicos, cujos temores se agravavam ante a obsessão 
"progressista" da esquerda, foi fácil para o candidato Trump valer-se do discurso contra o establishment político e acadêmico representado por Hillary Clinton. ${ }^{9}$ Multiplicando acusações contra minorias e imigrantes, a quem atribuía a culpa pelo desemprego de americanos, pelas drogas e pela criminalidade comum, as mesmas utilizadas por políticos populistas de cada país na Europa com resultados importantes, Trump nunca manifestara interesse por direitos humanos. Ao contrário, com uma agressividade inusual nas democracias do velho continente, mas eficaz no Marlborough country, terra dos cowboys e justiceiros idealizados por Hollywood, ele reforçava suas declarações com atitudes racistas e ostensivamente machistas. E nada disso se modificou depois que ele chegou ao poder, a não ser para adaptação em discursos de crítica ao sistema multilateral.

Com base em conversas que mantive em fevereiro de 2018, em Genebra, com colegas da Missão do Brasil e 30 funcionários do ACNUDH, a retirada dos Estados Unidos do $\mathrm{CDH}$, em junho de 2018, não teve ainda repercussões. O país tem continuado a atuar, em Nova York, no acompanhamento dos Relatórios Periódicos Universais. Em Genebra, não participa diretamente de nada, mas procura influir em negociações para a reforma do Conselho, agora em nova rodada. Atuam indiretamente, via aliados habituais desenvolvidos, alguns centro-americanos e pequenos países insulares, como Fiji e Samoa. Os objetivos são os mesmos: acabar com o item da agenda especificamente sobre Israel ${ }^{10}$ e obter limitações institucionais à entrada de membros

\footnotetext{
9 A quem parecer que estou fazendo "análise retrospectiva”, garanto que, com base em experiência de oito anos nos Estados Unidos (e 35 de Nações Unidas), eu já dizia isso antes de Trump ser eleito.

10 Sem levar em conta que, historicamente, foi o tratamento dispensado a palestinos nos territórios ocupados por Israel em 1967 e o sistema racista do apartheid sul-africano (que também recebia tratamento separado até sua abolição) que levaram a ONU a criar mecanismos para abordar violações de direitos humanos (ver Lindgren-Alves, 2011).
} 
violadores no $\mathrm{CDH}$. Suas propostas variam desde a simples adoção do voto secreto, para evitar constrangimentos bilaterais, à interdição de candidatura de Estados sob sanções.

A retirada dos Estados Unidos do $\mathrm{CDH}$ da ONU, esboçada nas entrelinhas da menção crítica de Trump a esse órgão em seu primeiro discurso na Assembleia Geral, em setembro de 2017, já era esperada ${ }^{11}$ - especialmente depois do anúncio da saída da Organização das Nações Unidas para a Educação, a Ciência e a Cultura (Unesco), em outubro do mesmo ano, juntamente com Israel. A ela se associavam o encerramento das contribuições ao Fundo de População das Nações Unidas (FNUAP), a retirada dos Acordos de Paris sobre o clima, do acordo com o Irã sobre o controle da produção nuclear iraniana, envolvendo parceiros europeus, e muitos outros gestos de menosprezo pelo multilateralismo. A impressão que se tem é de que o personalíssimo governo do presidente Trump não tem sequer a intenção, que o governo Bush ainda tinha, de manter o país como líder hegemônico de nada. ${ }^{12}$ A liderança pessoal que ele tenta impor autoritariamente dentro do país, com resultados contrários nas eleições parlamentares de outubro de 2018, enfrenta resistências decisivas da oposição, de agências do governo e do Judiciário em diversas instâncias.

\section{Efeitos das políticas de Trump sobre os direitos humanos no mundo}

Em maio de 2017, ao expor para funcionários a política externa America first ("América em primeiro lugar”), lema

\footnotetext{
11 Trump dizia ser "motivo de constrangimento enorme para as Nações Unidas o fato de alguns governos com históricos vergonhosos de direitos humanos fazerem parte do Conselho de Direitos Humanos" (Leia..., 2017).

12 Essa é a ideia que deu nome ao discurso do scholar brasileiro, funcionário do ACNUDH, Leonardo Castilho (2018), em seminário no Centro para Direitos Humanos da Universidade de Maastricht: United States' diplomacy and human rights in Trumpian times: the abandon of the hegemon. Muito agradeço a ele pelas anotações usadas, informações orais e documentação referencial que me cedeu.
} 
de Donald Trump como presidente, seu primeiro secretário de Estado, Rex Tillerson, já explicitava que os valores de liberdade e dignidade humana "são valores americanos", que não devem condicionar a busca do interesse econômico e de segurança na política externa (Finnegan, 2017). Isso sem pretender analisar iniciativas em campos diversos que, se não violam normas internacionais, seguramente vão contra direitos fundamentais de migrantes e imigrantes estabelecidos (inclusive crianças), prejudicam esforços pela igualdade racial, estigmatizam uma religião específica e reforçam discriminações contra latinos, muçulmanos e LGBTI.

É evidente, pelo simples exemplo, que a personalidade e as políticas de Trump têm efeito multiplicador alhures. Trata-se do país mais poderoso e rico do mundo, que sempre se apresentou como modelo. Seu distanciamento assumido do sistema internacional de direitos humanos, em conjunção com as iniciativas domésticas - menos graves que a "Guerra ao Terror" de Bush, com suas invasões e seu "Patriot Act", mas menos justificáveis -, pode ser visto, sim, como incentivo a governos violadores de direitos humanos. Isso é particularmente ominoso numa fase em que o ódio é viralizado pelas redes sociais, as divergências se polarizam e o mundo parece haver desistido da democracia liberal em favor do autoritarismo.

A paz entre adversários transformados em inimigos inconciliáveis, na linha de Carl Schmitt, além de socialmente excludente, é frágil, ameaçada à direita por pseudonacionalismos fanáticos e, à esquerda, pelo progressismo provocador, delimitado por objetivos grupais. Difícil é discernir quem influencia quem, num período em que o termo "democracia iliberal" cunhado por Viktor Orbán, no poder há muitos anos na Hungria, passou a ser repetido com naturalidade; quando os abusos dos falcões de Bush se acham absorvidos como faceta normal do mundo globalizado; quando a extrema direita se propõe a fundar uma "Internacional" dextrogira; quando o fundamentalismo religioso, protestante, 
católico, ortodoxo, xiita, sunita, sionista e hindu, se instala e se expande no poder. ${ }^{13}$ Pior ainda sabendo, por muitos casos recentes, que, nas palavras de Levitsky e Ziblatt (2018, p. 16), “o retrocesso democrático hoje começa nas urnas". É sintomático notar, fora do âmbito euro-americano, como um país como as Filipinas, que havia sofrido os horrores da ditadura de Ferdinando Marcos, reage à criminalidade presente com apoio a promessas de violência brutal praticadas e repetidas pelo governo do presidente Duterte, eleito antes de Trump. Do outro lado do mundo, pouco depois, mas na mesma época, outro candidato à presidência da República ganhava eleições majoritárias com gesto de quem dá tiros, depois de louvar a tortura do antigo regime militar, declarando que, para consertar o país, se deveria matar 30 mil.

\section{Estados Unidos, Brasil e americanização dos direitos}

Em setembro de 2001, pouco antes dos atentados às Torres Gêmeas, na sequência de outros eventos internacionais e tratados que já haviam então deixado, os Estados Unidos de Bush abandonaram a Conferência de Durban contra o Racismo por causa do viés anti-israelense que nela viam. Depois dessa retirada, como as negociações prosseguiam, cálidas em muitos temas, líderes do movimento negro norte-americano presentes disseram à delegação brasileira que passavam a considerar-se plenamente representados pelo Brasil. Claro que foi um incentivo bem-vindo à atuação dos delegados e às posições brasileiras, todas articuladas com a sociedade civil. Tais posições eram comuns, em muitos aspectos, com as de ONGs de outros países das Américas. Mas, a rigor, eram nossas. Depois disso, contudo, ninguém mais do Brasil, do Caribe e da América Latina em geral era negro, mestizo, nem, muito menos, mulato. Eram afrodescendentes. Isso foi só um caso, repetido em muitos outros.

13 Ver Harari (2018). 
Por mais que as diferenças entre os Estados Unidos e o Brasil sejam colossais, semelhanças também abundam. Em quase todas as áreas. As circunstâncias das eleições brasileiras de 2018 e das americanas de 2016 são tão parecidas que dispensam ilustrações. Não se pode, porém, afirmar que a eleição de Trump tenha determinado a eleição de Bolsonaro. Ambos azarões nas pesquisas, os candidatos tinham muitas diferenças. Um era rico, abusado, inflexível criador da "pós-verdade". Outro era tosco, de classe média, inseguro, reprodutor sem critério de invencionices alheias. Identificavam-se, porém, na permanente ojeriza às políticas de identidades, a tudo o que fosse ligado à proteção de minorias e valorização de diferenças. Pois foi o procedimento agressivo, de longa data, contra o "politicamente correto", que lhes deu popularidade. Do lado antagônico, ao contrário, as atitudes da militância de esquerda nos Estados Unidos e no Brasil são iguais há muito tempo, por influência da primeira. Moldadas por lideranças cultas, refletidas nos partidos políticos e magnificadas pela mídia, as posturas "progressistas", provocativas, da esquerda foram, nos dois países, fatores decisivos na vitória da direita.

Com as classes sociais esquecidas nos Estados Unidos e passadas a segundo plano no Brasil redemocratizado, cresciam, na academia, os "estudos culturais" de estilo norte-americano. Filhos da contracultura dos anos 1960 e 1970, tais estudos acentuam incessantemente o discurso racial diferencialista, ${ }^{14}$ o feminismo radical obsessivo,${ }^{15}$ as reivindicações

\footnotetext{
${ }^{14}$ Por discurso racial diferencialista refiro-me à tendência, compreensível quando o Brasil oficial e extraoficial negava o fator raça nas relações sociais, de preferir a autossegregação autêntica à suposta integração "cultural".

${ }_{15}$ A expressão é autoexplicativa. Feministas igualitários não obsessivos todos podemos ser. Obsessivo é o feminismo que tudo vê com a ótica do presente a fim de obter compensações variadas - eliminação de obras de arte "machistas", "correções" de contos de fadas, revisão da história para ressaltar o papel da mulher -, sem falar do feminismo neocapitalista que não perde oportunidade de extorquir dinheiro de alegados assediadores.
} 
demasiado específicas dos LBGTI, ${ }^{16}$ as cobranças multiculturalistas de linguagem e comportamento politicamente corretos. No mesmo sentido, no velho movimento pelos direitos humanos, a proteção de minorias se estendia para imigrantes, crianças e adolescentes assaltantes, famílias de infratores cumprindo pena, ao mesmo tempo que aumentavam as acusações preconceituosas contra a polícia, os policiais militares e forças do exército atuantes em operações legítimas. A isso se acresciam a exploração ad nauseam de ocorrências criminais trágicas, como o assassinato político da vereadora Marielle Franco em 2018, com cada grupo puxando o assunto para suas causas específicas, a constante morte de inocentes por balas extraviadas de policiais e traficantes de drogas, a alegação de um "genocídio de crianças negras", a qualificação enfática da sociedade brasileira como racista, machista, discriminadora e homofóbica. Longe de emocionar o público, assolado pela violência incontida, tudo isso distanciava o cidadão comum, cada dia mais irritado com o discurso dos direitos humanos, a falta de projetos abrangentes, a corrupção enviezadamente exposta e a omissão dos partidos de esquerda frente à criminalidade ubíqua.

Usando Estados Unidos e Brasil como exemplo, as tendências político-culturais desses dois países, na direita e na esquerda, eram e são semelhantes às de todo o continente americano, e crescentemente da Europa, feitas as adaptações necessárias. As distinções são de foco, conforme as circunstâncias de cada um: contra e a favor dos muçulmanos, ou judeus, ou xiitas, ou sunitas, ou hindus, ou cristãos, ou ciganos; contra e a favor dos imigrantes, das pessoas de outras tribos; feminismo ou misoginia; homofobia ou

16 A não discriminação, a proteção contra a violência, o respeito pela individualidade de homossexuais e assemelhados são direitos humanos universais. Algumas reivindicações especiais dos LBGTI podem vir a constituir direitos particularizados, mas são direitos locais, não necessariamente universalizáveis, por motivos econômicos ou culturais. A insistência neles fora de áreas compatíveis tem provocado, em muitos casos, reações fortíssimas, que pioram sua situação, até com novas leis repressivas. 
homofilia; contra e a favor dos negros, dos brancos, dos nativos, dos mestiços. As esquerdas, que defendem direitos humanos, dizem-se progressistas ao privilegiar minorias, e não classes, acima da ideia de nação. O centro aceita minorias que não perturbem o conjunto. A direita fala de identidade autêntica, assimiladora ou excludente, como componente una da nacionalidade, da pátria.

Apesar do abismo econômico existente ou não entre elas, quase todas as nações e quase todas as comunidades não isoladas, no mundo globalizado pelo mercado, pela internet e por Hollywood, com variações culturais, seculares ou religiosas, têm os Estados Unidos como referência e modelo de consumo. $\mathrm{O}$ mesmo ocorre com as instituições do sistema internacional, não em termos de consumo, mas de direitos, por comunidades.

\section{Críticas ao sistema}

Críticas construtivas ao sistema internacional de direitos humanos sempre houve, feitas por observadores, ativistas, atores e participantes. Elas se acentuaram na década presente, à medida que defeitos endógenos e exógenos se tornavam mais visíveis.

Logo depois da década de 1990, que tanto louvou e expandiu os direitos, Michael Ignatieff (apud Rieff, 2018) previa a "erosão do consenso" que havia dado apoio à Declaração Universal, pois nada levava a crer que a globalização econômica trouxesse "globalização moral" ${ }^{17}$ Em 2016, Kenneth Roth, diretor da Human Rights Watch, observava "como a política do medo e o esmagamento da sociedade civil põem em perigo os direitos humanos", passando a advertir, em 2017, que o incremento do populismo ameaçava "reverter as conquistas do movimento moderno dos

17 Eu próprio, em artigos diversos, alertava para esse problema desde 1998 (Lindgren-Alves, 2018b, pp. 301-304). 
direitos humanos" (apud Rieff, 2018). O que Roth queria dizer com "movimento moderno" não sei bem. Temo que ele se referisse aos avanços na política de identidades, encampada pela ONU e por organizações regionais. Tais avanços costumam ser realmente as primeiras vítimas do populismo de direita, mas sua vitimização decorre também da insistência exagerada das cobranças do "movimento moderno". E disso a própria Human Rights Watch participa.

Entre as críticas consistentes, antes da eleição de Trump, refletindo efeitos dos abusos neoconservadores do governo Bush, destaco as de Stephen Hopgood (2013), verdadeiro libelo contra violações cometidas pelos Estados Unidos, e as de Eric Posner (2014) sobre a expansão de instrumentos, o que torna inviável a observância de todos eles por qualquer país. ${ }^{18}$ Mais contundente, e posterior à eleição presidencial americana de 2016, é Philip Alston (2017, p. 268), cujo texto "Direitos humanos sob ataque: como reagir à ameaça populista que os direitos humanos enfrentam", começa pela afirmação: "O movimento de direitos humanos, como o conhecemos, não existe mais". Com crítica séria à atuação dos países ocidentais e dos atores não governamentais, Alston (2017) faz recomendações à "comunidade de direitos humanos" que incluem "reconhecer a necessidade de empregar mais tempo em sermos persuasivos e convincentes", "dar um passo atrás na prepotência" e "aprender a viver com restrições da vida real", sem desistir de "promover os valores mais importantes". Embora Philip Alston não tenha a clareza de Mark Lilla, entendo que essas recomendações conformam crítica cautelosa aos excessos na proteção dos diferentes, com superação da inflexibilidade abusiva do politicamente correto. Mas é Lilla, em seu pequeno livro de 2017 (Lilla, 2018), que diz o essencial daquilo que eu próprio penso, registrado

18 Esse é um dos pontos que analiso em estudo feito também no capítulo "As dificuldades atuais do sistema internacional de direitos humanos" (Lindgren-Alves, 2018b, pp. 33-66). 
particularmente em texto também de 2017 (Lilla, 2017): para a militância conseguir os avanços desejados é necessário que os partidos defensores de direitos cheguem ao poder pelos votos da cidadania. Isso não ocorreu nos Estados Unidos, nem no Brasil, em função também dos erros da própria militância.

Os direitos humanos na forma como são apresentados hoje, em defesa exclusiva de identidades, estas construídas sobretudo pela ação acadêmica e midiática, não somente se apresentam distorcidos como constituem um tema elitista. Não falam às necessidades maiores e mais imediatas do povo, nem usam a linguagem da maioria. Fornecem, ao contrário, o discurso elevado, o "progressismo" de novos mercados e do "empreendedorismo" como solução para o desemprego, por meio dos quais o poder tradicional e o capitalismo global de fachada se "modernizam". A militância distorcida e destemperada é também de origem ou inspiração norte-americana.

O "lugar de fala" é uma expressão brasileira - creio para a intolerância identitária sempre praticada nos Estados Unidos, que também começamos a importar. Assim como não é preciso ter sido torturado para ser contra a tortura, nem ser judeu para repudiar o Holocausto e combater o antissemitismo, não é preciso ser feminista para se opor à discriminação contra a mulher, para lutar por sua remuneração igual, para combater a violência doméstica, para prevenir e punir agressões baseadas em sexo. Não é preciso ser membro do grupo LGBTI para ser contra violência, preconceitos e discriminações contra homossexuais e assemelhados. Não é preciso ser negro, indígena ou etnicamente diferente para atuar em favor da ascensão social dos segmentos inferiorizados. Não é preciso ser minoria para ter direitos humanos.

Sei que o que digo aqui pode soar inoportuno num momento em que a educação no Brasil enfrenta ameaças assustadoras, baseadas em posições de extrema direita, algumas das quais se assemelham às minhas preocupações por 
motivos contrários. Lamentavelmente, tenho plena convicção de que as linhas seguidas pelos atuais militantes de direitos pouco falam ao eleitorado de classe média e baixa, ele próprio majoritariamente tosco, seduzido por propostas grosseiras e arraigadamente contrário ao que tem sido ensinado como politicamente correto. Ou os formadores de opinião, em escolas, movimentos sociais, televisão e outros meios de comunicação de massa, adotam novas abordagens, que deixem de marcar tanto as diferenças e incluam formas aceitáveis de combate legal à criminalidade, ou o sonho de progresso deixará de existir.

A par de minhas humildes postulações, isoladas e completamente ignoradas ao longo de vinte anos, depois do livro de Mark Lilla, de 2017, outros escritos americanos de analistas liberais têm aparecido em direção congênere, fora da área estrita dos direitos humanos. O mais visível talvez venha a ser o livro de Francis Fukuyama (2018b), Identidades, ${ }^{19}$ previamente resumido como artigo de título incisivo: "Against identity politics: the new tribalism and the crisis of democracy" ["Contra a política de identidades: o novo tribalismo e a crise da democracia”] (Fukuyama, 2018a). Espero que seja utilizado de maneira diferente do ocorrido com seu célebre "The end of history?" ["Fim da história?”] (Fukuyama, 1989), cujo triunfalismo já se achava atenuado em The end of history and the last man [O fim da história e o último homem] (Fukuyama, 1992). Pelo menos não me sentirei tão sozinho.

\section{Opções conclusivas}

Régis Debray (2017) tem um livro recente que descreve a maneira pela qual os franceses, tão ciosos de sua língua e cultura, hoje se encontram totalmente americanizados.

19 Seu título original, Identity: contemporary identity politics and the struggle for recognition, na tradução portuguesa é modificado para Identidades: a exigência de reconhecimento e a política de ressentimento. 
Se isso ocorre na França, chauvinista, cuja Luzes inspiraram o mundo moderno, o que dizer do Brasil, embasbacado de sempre pela "América", com a cultura brasileira questionada e fragmentada internamente por diversas matrizes? Na França, quem defende a "identidade autêntica" há mais tempo é a ultradireitista Marine Le Pen, que foi para o segundo turno das eleições presidenciais com Macron. Na Alemanha, a extrema direita entrou para o Parlamento, pela primeira vez depois da Segunda Guerra Mundial, com o movimento ultranacionalista, que muitos consideram racista, Allianz für Deutschland (AfD, Aliança pela Alemanha). Em outros países da Europa a direita está no poder. Em todos já se fala contra o "marxismo cultural" e o "globalismo", expressões inventadas pelos opositores.

Eis aí, muito por alto, no que dá o "modismo" das identidades coletivas. Radicalizado com ganhos pela direita, acaba indo contra tudo o que a esquerda defende. Mas isso, tal como a esquerda ilusoriamente "progressista" em casa, os órgãos internacionais e as ONGs mais atuantes não veem. Por que é que, depois de ter sido considerada judicialmente legítima pela Corte Europeia de Direitos Humanos, a proibição pela França do niqab - véu dito islâmico que esconde o rosto - em espaços públicos e escolas foi agora considerada violação de direitos pelo $\mathrm{CDH}$, órgão de controle do Pacto de Direitos Civis e Políticos (Neves, 2018)? Quem, afinal, viola os direitos de quem? A França, ao proteger os direitos individuais da mulher e a segurança de todos, ou o ativismo do Comitê do sistema ao proteger uma tradição estrangeira politizada, dada como religiosa, de uma minoria restrita dentro da própria comunidade muçulmana? Não fica, assim, tão difícil reinventar teorias sinistras de "conspiração globalista”, como tem feito a paranoia político-ideológica que ganha adeptos e eleições. ${ }^{20}$

${ }^{20}$ Para um apanhado histórico dessas teorias, ver Jaime Nogueira Pinto (2017). 
A política de identidades, mais do que os direitos humanos, é criação americana, como o são o movimento LGBTI e o fundamentalismo evangélico, a teologia da prosperidade e o televangelismo eletrônico, os talk shows humorísticos e a difusão sem controle do discurso do ódio, o armamentismo civil e a privatização das obrigações estatais. Ao condenar o ataque sanguinário cometido por jovens brasileiros suicidas em escola de Suzano (SP), em março de 2018, o presidente do Supremo Tribunal Federal, ministro Dias Toffoli, afirmou: "Violência como essa não faz parte de nossa cultura”. Pode-se replicar que não fazia. No Brasil já houve vários casos. Eles começaram onde? Quem é que sempre defendeu o "direito de portar armas"? Na antípoda Nova Zelândia, o assassino neozelandês que recentemente matou e feriu cem muçulmanos em uma mesquita, logo depois do episódio de Suzano, fez questão de deixar um manifesto em que cita o mau exemplo do Brasil, diverso e fraturado, enquanto elogia Trump.

Os defeitos do sistema, a importação de modelos inadaptáveis sem reações perigosas e as ameaças atuais têm dimensão planetária. A questão é decidir o que se quer defender. Não entre direita e esquerda. Nos votos, a escolha atual está feita. Mas decidir, sim, se os militantes devem persistir na linha contraproducente amargamente comprovada, ou desenvolver esforços realistas, capazes de envolver o conjunto das pessoas, sem descaracterizar as partes, individuais e coletivas. Para isso é imprescindível saber o que queremos: direitos universais, abrangentes, ou separações infinitas?

Revolução já não há; as utopias morreram. Direitos minimalistas, da Declaração Universal, ainda parecem poder ser mantidos. Num mundo retrógado isso também exige lucidez e coragem, na oposição democrática às forças poderosas que sempre serão contra eles. Pensando também em eleições. 


\section{José A. Lindgren-Alves}

é embaixador aposentado, primeiro diretor-geral do Departamento de Direitos Humanos e Temas Sociais do Ministério das Relações Exteriores (Brasília). Atualmente é membro do Comitê Assessor do Conselho de Direitos Humanos da ONU (Genebra). Autor do livro É preciso salvar os Direitos Humanos! (2018).

\section{Bibliografia}

ALSTON, Philip. 2017. Direitos humanos sob ataque: como reagir à ameaça populista que os direitos humanos enfrentam. Sur: Revista Internacional de Direitos Humanos, v. 14, n. 25, pp. 267-273.

BOLTON, John. 2006. Explanation of vote on the Human Rights Council Draft Resolution. Washington, DC: U.S. Department of State.

Disponível em: https://2001-2009.state.gov/p/io/rls/rm/63143.htm. Acesso em: 25 set. 2019.

CASTILHO, Leonardo. 2018. United States' diplomacy and human rights in Trumpian times: the abandon of the hegemon. Maastricht: Maastricht Centre for Human Rights.

DEBRAY, Régis. 2017. Civilization: comment nous sommes devenus Américains. Paris: Gallimard.

FINNEGAN, Conor. 2017. Tillerson: pushing human rights abroad 'creates obstacles' to US interests. ABC News, 3 maio 2017. Disponível em: https:/ /abcnews.go.com/Politics/tillerson-pushing-human-rightsabroad-creates-obstacles/story?id=47190743. Acesso em: 25 set. 2019.

FUKUYAMA, Francis. 1989. The end of history? The National Interest, n. 16, pp. 3-18.

FUKUYAMA, Francis. 1992. The end of history and the last man. New York: The Free Press.

FUKUYAMA, Francis. 2018a. Against identity politics: the new tribalism and the crisis of democracy. Foreign Affairs, set./out. 2018.

FUKUYAMA, Francis. 2018b. Identity: contemporary identity politics and the struggle for recognition. London: Profile Books.

HARARI, Yuval Noah. 2018. 21 lessons for the 21st century. Londres: Penguin. HERNANDEZ, Matheus de Carvalho; ROCHA, William Torres Laureano da. 2018. Os EUA e a revisão periódica universal do Conselho de Direitos Humanos da ONU. Estudos Internacionais, v. 6, n. 1, pp. 127-149.

HOPGOOD, Stephen. 2013. The endtimes of human rights. Ithaca: Cornell University Press, 2013. 
LEIA a íntegra do discurso de Donald Trump na ONU. 2017. Tradução: Clara Allain. Folha de S.Paulo, São Paulo, 19 set. 2017 Disponível em: http:/ / bit.ly/36dYTUI. Acesso em: 25 set. 2019.

LEVITSKY, Steven; ZIBLATT, Daniel. 2018. Como as democracias morrem. Tradução: Renato Aguiar. Rio de Janeiro: Zahar.

LILLA, Mark. 2017. Metamorfoses dos direitos humanos. Revista USP, n. 115 , pp. 29-40.

LILLA, Mark. 2018. De esquerda, agora e sempre: para além das políticas identitárias. Tradução: João Brandão. Lisboa: Tinta da China.

LINDGREN-ALVES, José A. 2005. Excessos do culturalismo: pósmodernidade ou americanização da esquerda? In: LINDGREN-ALVES, José A. Os direitos humanos na pós-modernidade. São Paulo: Perspectiva, pp. 89-110.

LINDGREN-ALVES, José A. 2011. Os direitos humanos como tema global. 2. ed. São Paulo: Perspectiva.

LINDGREN-ALVES, José A. 2018a. A década das conferências. 2. ed. Brasília, DF: Funag/Ipri.

LINDGREN-ALVES, José A. 2018b. É preciso salvar os direitos humanos!. São Paulo: Perspectiva.

MARX, Karl. 2010. Sobre a questão judaica. Tradução: Nelio Schneider. São Paulo: Boitempo.

NEVES, Lucas. 2018. França viola direitos humanos ao proibir véu islâmico, diz ONU. Folha de S.Paulo, 24 out. 2018.

PINTO, Jaime Nogueira. 2017. Bárbaros e iluminados: populismo e utopia no século XXI. Alfragide: Dom Quixote.

POMPEO, Mike; HALEY, Nikki. 2018. Remarks on the UN Human Rights Council. Washington, DC: U.S. Department of State. Disponível em: http:/ /bit.ly/2Wn5TKB. Acesso em: 25 set. 2019.

POSNER, Eric. 2014. The twilight of human rights law. Oxford: Oxford Univerity Press.

RIEFF, David. 2018. The end of human rights? Foreign Policy, 9 abr. 2018. 


\section{DIREITOS UNIVERSAIS OU AMERICANIZAÇÃO TOTAL?}

JOSÉ A. LINDGREN-ALVES

Resumo: Os direitos humanos, supostamente disseminados pelos Estados Unidos, sempre foram por eles utilizados como instrumento de propaganda. Tão exitosos foram nessa manipulação que, até hoje, quando observadores demonstram surpresa com as iniciativas de Trump, entre as quais a de abandonar o Conselho de Direitos Humanos da Organização das Nações Unidas (ONU), tendem a encará-las como gestos novos de uma liderança absurda. A realidade é diferente. Enquanto Donald Trump representa uma caricatura amedrontadora de tendências planetárias atuais, a seletividade norte-americana na área é perene, a instrumentalização do sistema é igual à de sempre, e os alvos preferenciais, parecidos. Em contraste com o passado, contudo, os efeitos agora, num cenário global de autoritarismos crescentes, são muito mais ominosos. Por outro lado, também por influência norte-americana, mas da sociedade civil, os direitos alardeados não são mais os da Declaração Universal de 1948. Este estudo aponta os marcos dessa minha preocupação de sempre, assim como a possibilidade de refocalização nos direitos de todos como alternativa à americanização falseada das sociedades existentes.

Palavras-chave: Direitos Humanos; Direitos de Minorias; Políticas de Identidade; Estados Unidos; Trump; ONU; Eleições Brasileiras; Esquerda e Direita.

\section{UNIVERSAL RIGHTS OR TOTAL "AMERICANIZATION"?}

Abstract: Whereas supposedly disseminated by the United States, human rights have always been used by it as a tool of propaganda. It was so successful in their manipulation that, up to now, when observers show surprise at President Trump's initiatives, such as 
quitting the United Nations' Human Rights Council, they tend to be seen as new gestures of an absurd leadership. Although indeed Trump seems a frightening caricature of current worldwide trends, selectivity in this area has been continuous; instrumental use of the human rights system is the same as always, and the US targets remain similar. In contrast with the past, however, present effects, in a global scenario of growing authoritarianism, are far more ominous. On the other hand, also by American influence, but coming from civil society, rights promoted are no longer those of the Universal Declaration of 1948. This paper points to the marks of these constant concerns of mine and to the possibility of a renewed focus on the rights of every person as an alternative to the false "Americanization" of existing societies.

Keywords: Human Rights; Minority Rights; Politics of Identity; United States; Trump; United Nations; Brazilian Elections; LeftRight Political Spectrum.

Recebido: 08/04/2019 Aprovado: 13/09/2019 